\title{
Comparing Collaboration with Cooperation in Game-Based Learning
}

\author{
Youngkyun Baek ${ }^{1, a}$, Hui Zhang ${ }^{2, b}$, Seongchul Yun ${ }^{3, c}$, and Xiangzhe Cui ${ }^{4, d}$ \\ ${ }^{1}$ College of Education, Boise State University, 1910 University Drive, Boise, ID, USA; \\ ${ }^{2}$ College of Education, Yanbian University, No.977 Gongyuan Street, Yanji, Jilin, China \\ ${ }^{3}$ Korea National University of Education, Cheongju-si, South Korea \\ ${ }^{4}$ College of Education, Yanbian University, No.977 Gongyuan Street, Yanji, Jilin, China \\ ayoungkyunbaek@boisestate.edu, ${ }^{\mathrm{b}}$ zimzhang@sina.cn, ${ }^{\mathrm{c} 04 y s c @ h a n m a i l . n e t, ~}$ \\ dcuixzhe@ybu.edu.cn
}

Keywords: Collaboration, cooperation, game based learning

\begin{abstract}
This paper aims to explore the concepts of collaboration and cooperation in game-based learning. Game play requires certain kinds of competition whether it is competing against other players or simply against the game itself. More importantly, as social games have become popular in recent years, social activities, such as collaborative gaming, have drawn educators' attention to gamebased learning. However, a conceptual differentiation between collaboration and cooperation should be identified and applied in game-based learning, so that learning outcomes can be attained effectively. In this regard, the definitions, principles, and cases of both collaboration and cooperation in game-based learning will be explored and discussed in this short paper.
\end{abstract}

\section{Introduction}

Game-based learning is being widely implemented into different fields. Collaborative and cooperative learning have been popular topics of discussion in teaching and learning in both traditional classrooms and game based environments. Specifically, there have been several discussions about the participation ways of collaboration and cooperation in game- based learning. In this paper, we highlight the definitions and principles of collaboration and cooperation as well as a case, which embodied collaboration and cooperation. Next, we address some of the main differences and the contrary arguments toward collaboration and cooperation in game- based learning.

\section{Definitions}

Collaboration. Collaboration is a philosophy of interaction and personal lifestyle where individuals are responsible for their actions, which include learning and respecting the abilities and contributions of their peers, and perform actions in the environment towards a common goal (Beznosyk, Quax, Coninx \& Lamotte, 2011; Panitz, 1999). According to the Oxford English Dictionary, the term "collaborate" originated in the late 19th century from the Latin word collaborat, which means "worked with" and from the verb collaborare (from col "together" + laborare "to work"); thus, the word collaborate means to work with each other towards the same goal, but not necessarily cooperatively on the same tasks (Davidson \& Major, 2014).

Collaborative learning. Collaborative learning is not limited to the process of students working together in groups, it also emphasizes working together as a group with the teacher in an effort to develop knowledge, thus shifting the nature of authority in the classroom (Davidson \& Major, 2014). As Smith and MacGrefor (1992) pointed out, collaborative learning is an umbrella term for a variety of educational approaches involving joint intellectual effort by students, or students and teachers together.

Cooperation. Cooperation is a structure of interaction designed to facilitate the accomplishment of a specific end product or goal through people working together in groups (Panitz, 1999). According to the Oxford English Dictionary, the term "cooperate" originated in the late 16th century from the 
Latin word "cooperat", which means "worked together", and from the verb "cooperari" (from co "together" + operari "to work"). In other words, to cooperate is to work together jointly to complete an educational operation, such as activity or a project (Davidson \& Major, 2014). Users simultaneously act on the same objects in a shared environment, which includes subtasks with a common goal first distributed among different actors (Beznosyk et al., 2011; Altin \& Pedaste, 2013).

Cooperative learning. Cooperative learning can be defined as students working together in a group, small enough that everyone can participate in a collective task that has been clearly assigned. Moreover, students are expected to carry out their task without direct and immediate supervision of the teacher. The study of cooperative learning should not be confused with small groups that teachers often compose for the purpose of intense, direct instruction-for example, reading groups (Cohen, Brody, \& Sapon-Shevin, 1994, p. 3). Cooperative learning is the instructional use of small groups so that students work together to maximize their own and each other's learning (Johnson, Johnson, \& Smith, 2013). Cooperative learning (CL) refers to students working in teams on an assignment or project under conditions in which certain criteria are satisfied, including that the team members be held individually accountable for the complete content of the assignment or project (Felder \& Brent, 2007).

\section{Principle}

Principles of Collaborative learning. 1. Working together results in a greater understanding than would likely have occurred if one had worked independently. 2. Spoken and written interactions contribute to this increased understanding. 3. Opportunity exists to become aware, through classroom experiences, of relationships between social interactions and increased understanding. 4. Some elements of this increased understanding are idiosyncratic and unpredictable. 5. Participation is voluntary and must be freely entered into (Panitz, 1999).

Principles of cooperative learning. 1. Positive interdependence. Each student in the same group has a unique contribution to make to the joint effort. Team members rely on one another to achieve the goal. Each group member's effort is required and indispensable for group success. 2. Individual accountability. All students in a group must be accountable for contributing their own share of the work and mastering all of the material to be learned for the group's success. 3. Face-to-face positive interaction. Although some of the group work may be parceled out and done individually, some must be done interactively, with group members providing one another with feedback, challenging reasoning and conclusions, and perhaps most importantly, teaching, helping, supporting, applauding and encouraging one another in order to reach the group's goals. 4. Appropriate use of social, interpersonal, collaborative and small-group skills. Students are encouraged and helped to develop and practice trust-building, leadership, decision-making, communication, and conflict management skills. 5. Group processing. Team members set group goals, describe what member actions are helpful or not, periodically assess what they are doing well as a team, and identify changes they will make to function more effectively in the future (Johnson, Johnson, \& Holubec, 1991; Kagan, 1994).

\section{Cases of collaboration and cooperation in game- based learning}

In order to compare how collaboration and cooperation influence users' enjoyment in a game- based environment, Beznosyk et al. (2011) carried out an experiment. In this paper, however, we specifically focus on highlighting the distinct applications of collaboration and cooperation into gaming, rather than the different outcomes of users' enjoyment. During the experiment, ten groups of three people were sequentially asked to play a basic 3D game with the shared goal of collecting 20 digits in the environment together with two partners. The game was represented as an environment that consisted of two virtual houses containing 20 cubes. Half of these cubes had a digit on one of their sides. In order to successfully complete the game, participants were asked to calculate the sum of all digits, and then to select the correct number (corresponding to the calculated sum) out of four options, presented as a four-item menu. To explore the environment, participants had to select and manipulate objects. For every session a different environment was created with the same level of 
complexity.

Collaborative session. Every object could be moved or rotated by a single person.

Cooperative session. One type of object could be manipulated by one user, which was similar to the collaborative session. Another type of object required joint manipulation by two users. If an object of the second type was selected, a help message was generated to inform other participants within the same house in the virtual environment that there was a person requiring a partner's help. However, the message did not indicate who triggered the call for help and where that person was located. Participants had to discuss this event to discover the feasibility of helping each other.

\section{Differences between collaboration and cooperation in game- based learning}

The role of the instructor. Cooperative learning tends to require more instructor intervention in structuring the groups and learning activities as opposed to collaborative learning where the instructor functions more as a facilitator in a game- based environment (Dillenbourg, Baker, Blaye, \& O'Malley, 1996; Bado \& Franklin, 2014).

Fields of application. Collaborative learning is more suited to be used in the fields of humanities, some of the social sciences, but rarely in other sciences or professional programs. Cooperative learning has been used mainly in the sciences, mathematics and engineering, social sciences, and professional programs (Davidson \& Major, 2014).

Participation ways. Kozar (2010) considered that cooperation is more focused on working together to create an end product, while successful collaboration requires participants to share in the process of knowledge creation (Dillenbourg et al., 1996; Roschelle \& Teasley 1995). In other words, cooperation can be achieved if all participants do their assigned parts separately and bring their results to the table. To illustrate this concept better, we provide an example of a cooperative activity using the game of Minecraft as a context of play. In this example. a group of four students are assigned to design a commercial building. Since this is a cooperative learning activity, each student in the group can assume a specific role within the activity. Specifically, one student may be in charge of designing the building, a second student can be the bookkeeper who ensures that the project stays within budget, while the other two students can be the builders and divide tasks accordingly. In this example, each user's participation and contribution is unique in that players rely on each other, while holding personal accountability for contributing their parts. Without a doubt, teacher intervention is needed to ensure effective communication between group members and to assess social skills. A teacher should also reinforce collaborative behaviors in the process and interview students if needed.

In contrast, collaboration implies direct interactions among individuals to produce a product and involves negotiations, discussions, and accommodating others' perspectives. To illustrate a collaborative learning scenario in game-based learning, we use the example of a Minecraft activity where students are asked, in groups, to replicate the Tang Dynasty capital city of Chang'an in Medieval China. For this assignment, students would need to research the city and learn about the cultural aspects of the city. They could also include historical facts on info blocks outside the buildings they recreate. In this specific case, as students share facts with another, they acquire more knowledge than if they had worked independently. Additionally, participants would discuss and negotiate certain aspects of the task such as the location of the building or the accuracy of a building design. More importantly, these negotiations among group members involve careful considerations of others' perspectives based on their research of the topic of exploration. The teacher's role in this case is primary focused on providing instructions and directions before the activity start. However, during the collaborative learning activity, participants are given more freedom to peer learn and peer teach. Overall, in the above case, the authors believed that the collaborative session was manipulated by one single person while cooperative session required discussion and teamwork among the participants.

\section{Discussion and conclusion}

Taken in sum, collaborative learning refers to how participants work together in groups to share in 
the process of knowledge creation, with the teacher acting more as a facilitator. Cooperative learning, on the other hand, takes place when participants focus on working together to create an end product, requiring more teacher intervention. In the context of game-based learning, the main differences between the two concepts reside in the skills players are required to contribute during gameplay to reach the final goal, as well as the degree of teacher intervention. In other words, players who play collaboratively to accomplish game tasks with negotiations and discussions; whereas they play cooperatively through their own assigned parts that lead to the final goal. In this paper, we have discussed specific cases and examples of collaborative and cooperative activities in game-based learning. That being said, we have concluded that collaboration and cooperation are two different concepts with regard to teacher's role, fields of application, and participation ways.

As game-based learning is becoming more popular in today's classrooms, an understanding of how collaborative and cooperative gaming activities are structured may help educators better address the learning outcomes. This will also help them design effective gaming activities that successfully align outcomes with specific targeted skills. Above all, collaborative and cooperative learning have been used interchangeably, thus creating ambiguity on what specific skills should be targeted in each type of activity. Lastly, a proper understanding of how collaborative and cooperative gaming activities differ can determine the level of teacher involvement and intervention and which of the two approaches is more suitable to teaching specific curricular subjects,

\section{References}

[1] Beznosyk, P. Quax, K. Coninx, W. Lamotte, User Enjoyment and Performance in Collaborative and Cooperative Games in Shared 3d Virtual Environments, Conference: GRAPP 2011 - Proceedings of the International Conference on Computer Graphics Theory and Applications, Vilamoura, Algarve, Portugal, March 5-7, 2011.

[2] B.L. Smith, J.T. MacGregor, What is collaborative learning? In M. Maher A.M. Goodsell and V. Tinto, editors, Collaborative learning: A sourcebook for higher education, 10-30. National Center on Postsecondary Teaching, Learning and Assessment, 1992.

[3] D.W. Johnson, R.T. Johnson, E.J. Holubec, Cooperation in the classroom, Edina, MN: Interaction Book Company, 1991.

[4] D.W. Johnson, R.T. Johnson, K.A. Smith, Cooperative learning: Improving university instruction by basing practice on validated theory, Journal on Excellence in College Teaching. 25(3\&4), 85-118, 2013.

[5] E.G. Cohen, C.M. Brody, M. Sapon-Shevin, Teaching cooperative learning: The challenge for teacher education. Albany, NY: SUNY Press, 2004.

[6] H. Altin, M. Pedaste, Learning approaches to applying robotics in science education, Journal of Baltic Science Education. 12 (3) 365-377, 2013.

[7] J. Roschelle, S. Teasley, The construction of shared knowledge in collaborative problem solving, In C. E. O’Malley (Eds.), Computer supported collaborative learning, Heidelberg: Springer-Verlag, 1995, 69-97.

[8] N. Bado, T. Franklin, Cooperative Game-based Learning in the English as a Foreign Language Classroom, Issues and Trends in Educational Technology. 2 (2) 1-17, 2014.

[9] N. Davidson, C.H. Major, Boundary crossings: Cooperative learning, collaborative learning, and problem-based learning, Journal on Excellence in College Teaching. 25 (2014) 7-55.

[10] Kozar, Towards better group work: Seeing the difference between cooperation and collaboration, In English Teaching Forum. 48 (2010) 16-23.

[11] P. Dillenbourg, M. Baker, A. Blaye, C. O'Malley, The evolution of research on collaborative learning, In E. Spada, P. Reiman (Eds.), Learning in humans and machine: Towards an interdisciplinary learning science, Oxford: Elsevier, 1996, 189-211.

[12] R.M. Felder, R. Brent, "Cooperative Learning," in P.A. Mabrouk (Eds.), Active Learning: Models from the Analytical Sciences, Washington, DC: American Chemical Society, 2007, ACS Symposium Series 970, Chapter 4, 34-53.

[13] S. Kagan, Cooperative Learning, Resources for Teachers, San Juan Capistrano, CA: Kagan Cooperative Learning, 1994.

[14] T. Panitz, Collaborative versus cooperative learning: A comparison of the two concepts which will help us understand the underlying nature of interactive learning, ERIC Document Reproduction Service No. ED448444. (1999a) 